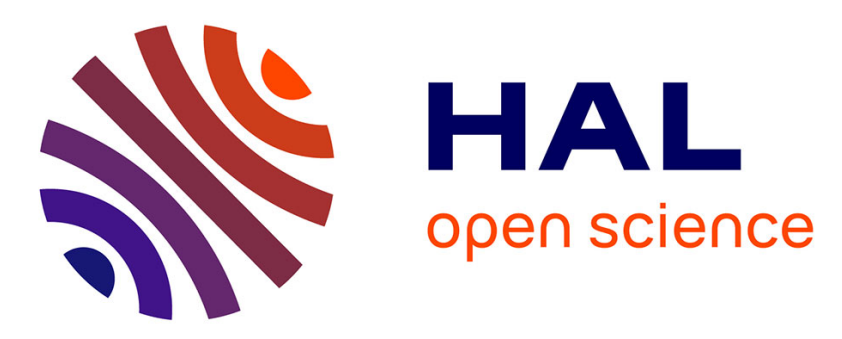

\title{
Effect of thermal oxidation on the self-assembly of triblock terpolymers
}

\author{
Juan Sebastian Montana, Sébastien Roland, Guillaume Miquelard Garnier, \\ Emmanuel Richaud
}

\section{> To cite this version:}

Juan Sebastian Montana, Sébastien Roland, Guillaume Miquelard Garnier, Emmanuel Richaud. Effect of thermal oxidation on the self-assembly of triblock terpolymers. Polymer Degradation and Stability, 2017, 146, pp.229-239. 10.1016/j.polymdegradstab.2017.10.013 . hal-01630815

\section{HAL Id: hal-01630815 https://hal.science/hal-01630815}

Submitted on 8 Nov 2017

HAL is a multi-disciplinary open access archive for the deposit and dissemination of scientific research documents, whether they are published or not. The documents may come from teaching and research institutions in France or abroad, or from public or private research centers.
L'archive ouverte pluridisciplinaire HAL, est destinée au dépôt et à la diffusion de documents scientifiques de niveau recherche, publiés ou non, émanant des établissements d'enseignement et de recherche français ou étrangers, des laboratoires publics ou privés. 


\title{
Effect of thermal oxidation on the self-assembly of triblock terpolymers
}

\author{
By Juan Sebastian Montana, Sébastien Roland, Guillaume Miquelard Garnier, \\ Emmanuel Richaud*
}

Arts et Métiers ParisTech, CNRS, CNAM, PIMM UMR 8006, 151 bd de l'Hôpital, Paris, France

\begin{abstract}
A B S T R A C T
This paper reports an investigation of the thermal degradation of a poly(styrene- $b$-butadiene- $b$-methyl methacrylate) triblock terpolymer compared with those of butadiene rubbers and poly(styrene- $b$-methyl methacrylate). According to sol-gel properties changes, it was proposed that polybutadiene blocks undergo mainly crosslinking. However, these latter coexist with chain scissions occurring in polybutadiene blocks, which generates poly (butadiene- $b$-methyl methacrylate) and poly(butadiene-b-styrene) diblock chains, and possibly chain scissions occurring in polystyrene and poly(methyl methacylate) blocks. The consequences of the degradation on the selfassembly of triblock terpolymer were studied through the annealing kinetics monitored by Atomic Force Microscopy. It appears that at low conversion degrees, chain scissions induce a faster self-assembly kinetics. At higher oxidation degrees, crosslinking of butadiene phase combined with scissions induces a "frozen" state at high annealing times characterized by a macrophase separation.
\end{abstract}

\section{Introduction}

Triblock terpolymers are made of immiscible segments linked by covalent bonds. Their self-assembly has aroused a considerable amount of literature in the last decade, since those materials can spontaneously arrange in several nanoscopic structures depending on tunable physicochemical characteristics such as the nature and the relative proportion of each monomer and the polymerization degree of each block $[1,2]$.

In the simple case of diblock copolymers, the equilibrium morphology (e.g. lamellar, cylindrical, gyroidal ...) is predicted from a phase diagram " volume fraction vs $\chi . \mathrm{N}$ » ( $\chi$ being the Flory interaction parameter and $\mathrm{N}$ the polymerization degree) expressing the effect of the enthalpy/entropy balance on self-assembly. To summarize, low values of $\chi . N$ correspond to a disordered state where all components are miscible, whereas "high" $\chi$.N values correspond to ordered states [3]. A phase separation occurs when the $\chi . N$ parameter increases, which happens for example when the temperature decreases at a so-called Order-Disorder transition temperature $\left(\mathrm{T}_{\mathrm{ODT}}\right)$ [4]. To the best of our knowledge, most of the previous researches paid attention to the nature of morphology corresponding to the thermodynamic equilibrium, and changes in properties induced by the self-assembly of diblock copolymers or triblock terpolymers.

Poly(styrene- $b$-butadiene- $b$-methyl methacrylate) triblock terpolymer (SBM in the following) materials are increasingly used, for example as impact modifiers for glassy polymers such as epoxies [5] or poly(2,6-dimethyl-1,4-phenylene ether) [6] for which the manufacturing can require a processing stage at high temperatures. SBM chains can thus be submitted to thermomechanical stresses. The possible subsequent degradation may modify the sought equilibrium morphology.

We were thus interested in the effect of thermally induced structural modifications on the ability of those triblock terpolymers to self-assemble. The degradation of random $[7,8]$ or block $[9,10]$ styrene butadiene copolymers is already reported in the literature. The detrimental role of the allylic hydrogens of polybutadiene is clearly evidenced. However, apart from a pioneering work on the self-assembly of oxidized poly(styrene-b-butadiene) block copolymers [10], most of the studies paid attention to the identification of oxidation products, but the consequences of oxidation on the macromolecular architecture and the triblock terpolymers ability to self-assemble remains an open question.

The main aim of this paper is hence first to study the degradation of a SBM material. For that purpose, its thermal oxidation will be investigated at a macromolecular level, and tentatively compared with the case of pure polybutadiene (PB) and poly(styrene- $b$-methyl methacrylate) block copolymers (PS- $b$-PMMA) so as to better ascribe the degradation mechanism. Then, the link between thermal oxidation state and self-assembly is examined. For that purpose, we will first compare self-assembly under vacuum or under air, and later the self-

\footnotetext{
* Corresponding author.

E-mail address: emmanuel.richaud@ensam.eu (E. Richaud).
} 
assembly of SBM materials with various "oxidation levels" representing, in a first approach, the possible consequences of degradation during the manufacturing process.

\section{Experimental}

\subsection{Materials}

The commercial SBM (which was thoroughly characterized in a previous publication [11]) was kindly supplied by Arkema. As shown by the GPC chromatogram in 'Appendix A', it is actually a mixture of triblock SBM chains and diblock SB chains. SBM chains have a molar mass $\mathrm{M}_{\mathrm{n}}$ about $100 \mathrm{~kg} \mathrm{~mol}^{-1}$ with molar masses of PS, PB and PMMA blocks respectively close to 20,20 and $60 \mathrm{~kg} \mathrm{~mol}^{-1}$. SB chains (being a precursor of SBM) have a molar mass about $40 \mathrm{~kg} \mathrm{~mol}^{-1}$. The molar masses of PS, PB blocks are respectively close to 20 and $20 \mathrm{~kg} \mathrm{~mol}^{-1}$. The weight ratio of di- and triblock is close to $45 / 55$. According to ${ }^{1} \mathrm{H}$ NMR data, the ratio of 1-4 cis/1-4 trans/1,2 units is about 45/45/10. The $\mathrm{T}_{\mathrm{ODT}}$ is close to $250{ }^{\circ} \mathrm{C}$ for this SBM grade as suggested in Ref. [11]. SBM was studied under three different forms:

- First, as received without further purification (to study the self-assembly). This material will be denoted $\mathrm{SBM}_{\mathrm{T}+\mathrm{D}+\mathrm{Aox}}$ ( $\mathrm{T}$ for Triblock, D for Diblock and Aox for antioxidants, those notations will also be used in the following).

- Secondly, after purification by dissolution in chloroform (ref 8.22265.1000 from VWR) followed by precipitation in methanol (ref 8.22283.1000 from VWR) and subsequent drying under vacuum to remove the processing antioxidants. Purified SBM flakes were pressed using a Gibrite laboratory press $\left(160^{\circ} \mathrm{C}, 30 \mathrm{~s}\right)$ between two Teflon sheets. This purified material was used for the ageing studies so as to highlight the effect of ageing on self-assembly. This material will be denoted $\mathrm{SBM}_{\mathrm{T}+\mathrm{D}}$.

- Last, after purification in heptane to remove the diblock (so as to study the effect of the diblock on the self-assembly). This material will be denoted $\mathrm{SBM}_{\mathrm{T}}$.

Some comparisons were done with model systems with simpler structure than SBM so as to better understand the reactivity towards oxidation:

- PS-b-PMMA block copolymer with an average number molar mass $M_{n}=32 \mathrm{~kg} \mathrm{~mol}^{-1}$, and block ratio of 2:1 (ref 739553 from Sigma Aldrich).

- a 98\% cis polybutadiene (ref 181374 from Sigma Aldrich) with an average molar mass in weight about $200-300 \mathrm{~kg} \mathrm{~mol}^{-1}$ denoted as PB1.

- a $36 \%$ cis $+55 \%$ trans $+9 \%$ vinyl polybutadiene (ref 181382 from Sigma Aldrich) with an average molar mass in weight about $200 \mathrm{~kg} \mathrm{~mol}^{-1}$ denoted as PB2.

Since SBMs under study contain a mixture of $1,2 \mathrm{cis}, 1,4$ trans and 1,2 units, the two butadiene rubbers were chosen to evaluate the effect of cis - trans - vinyl ratio on overall kinetics. Both polybutadienes PB1 and PB2 were also purified by dissolution in chloroform followed by precipitation in methanol and subsequent drying under vacuum. They were then pressed as above described and stored in a fridge prior to exposure.

\subsection{Sample preparation by spin coating}

SBM thin films of $45 \mathrm{~nm}$ thickness were obtained using an SPS 150 Europe spin-coater. Silicon wafers (ref W2301 from SIL'TRONIX silicon technologies) of 2 inches $(50.8 \mathrm{~mm})$ diameter were used as substrate, and SBM solution in toluene (purity $\geq 99.5 \%$ AnalaR NORMAPUR ${ }^{\circ}$ ACS) at $1.5 \mathrm{wt} \%$ was spin-coated at $4500 \mathrm{rpm}$ with a fixed acceleration of $4000 \mathrm{rpm} \mathrm{s}^{-1}$. The films were then annealed under vacuum at $170{ }^{\circ} \mathrm{C}$ for $72 \mathrm{~h}$. Atomic Force Microscopy (AFM) images were taken at different annealing times to observe the SBM nano-structuration changes (experimental details for AFM are given below).

\subsection{Ageing}

Samples were aged at $120{ }^{\circ} \mathrm{C}$ under air in ventilated ovens.

\subsection{Characterization}

\subsubsection{ThermoGravimetric analysis (TGA)}

TGA analyses were performed using a Q50 device (TA Instruments) driven by Q Series explorer. Samples were directly cast in the TGA pan from chloroform and aged in situ after vacuum drying so as to remove residual solvent traces. They were in situ isothermally aged at $120{ }^{\circ} \mathrm{C}$ under air atmosphere obtained from GazMix $\left(50 \mathrm{~mL} \mathrm{~min}^{-1}\right)$. Results were analyzed using TA Analysis software.

\subsubsection{Differential scanning calorimetry (DSC)}

About $5 \mathrm{mg}$ samples sealed in aluminum pans were subjected to a heating ramp from room temperature to $300{ }^{\circ} \mathrm{C}$ at a rate of $10{ }^{\circ} \mathrm{C} \mathrm{min}-1$ under inert atmosphere supplied by a $50 \mathrm{~mL} \mathrm{~min}^{-1}$ nitrogen flow. Measurements were performed using a Q10 apparatus (TA Instruments) driven by Q Series Explorer. Data were analyzed using TA Analysis software.

\subsubsection{Sol gel analysis}

Aged samples (mass $\mathrm{m}_{0}$ about $40 \mathrm{mg}$ ) were immerged into chloroform during $24 \mathrm{~h}$ at room temperature. After immersion, samples were weighted at swollen state (mass $\mathrm{m}_{\mathrm{S}}$ ), dried until the mass is constant (mass $\mathrm{m}_{\mathrm{D}}$ ). Samples were mainly characterized by the gel fraction $\mathrm{m}_{\mathrm{D}}$ / $\mathrm{m}_{0}$.

\subsubsection{GPC analysis}

Soluble part of samples were analyzed by high-temperature gel permeation chromatography (GPC; Agilent $220 \mathrm{HT}$ with RI detection) at $50{ }^{\circ} \mathrm{C}$ using 1,2,4-trichlorobenzene (CHROMASOLV ${ }^{\circ}$, 99\% grade from Sigma Aldrich stabilized with $0.0125 \%$ BHT) as solvent and

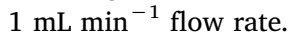

\subsubsection{Atomic Force Microscopy (AFM)}

AFM tapping mode images were obtained by using a Multimode microscope driven by a Nanoscope V controller (Veeco) and operated under ambient atmospheric conditions. The tips (silicon, spring constant $40 \mathrm{~N} \mathrm{~m}^{-1}$, oscillation frequency about $300 \mathrm{kHz}$ ) were obtained from BudgetSensors, with a radius of curvature of less than $10 \mathrm{~nm}$. Height, amplitude and phase images were acquired simultaneously, but only the latter allowed the micro-phase separation of each polymer block to be identified. Images were recorded with a resolution of $512 \times 512$ pixels and a scan rate of $0.8 \mathrm{~Hz}$. These settings yield a pixel size of $4 \mathrm{~nm}$.

\section{Results}

\subsection{Morphology of self-assembled unaged and aged SBM}

$\mathrm{SBM}_{\mathrm{T}}$ was thermally annealed at $120{ }^{\circ} \mathrm{C}$ under vacuum. AFM pictures are presented in Fig. 1a. An equilibrium morphology is reached after roughly $14 \mathrm{~h}$. This morphology can be commented as follows. In the bulk, a lamellar morphology appears, consistent with rheological measurements showing that $\mathrm{G}^{\prime \prime}$ changes with $\omega^{0.5}$ in the terminal zone below the expected temperature of order-disorder transition [11]. PB blocks organize at the periphery of styrene as already described elsewhere $[12,13]$. This "core" is surrounded by a corona of PMMA lamellae. At the surface, the polymer/air interface tension triggers in 

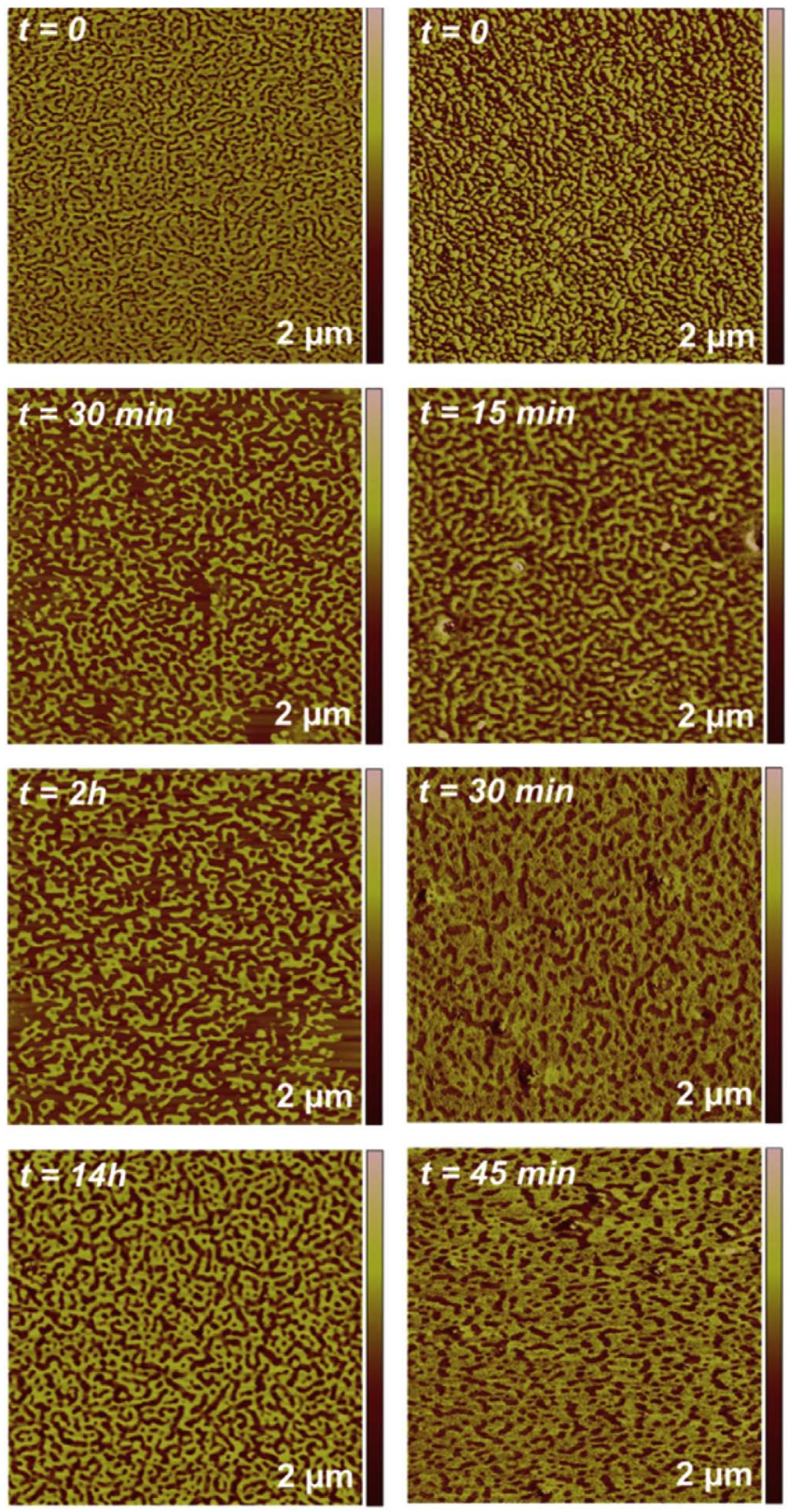

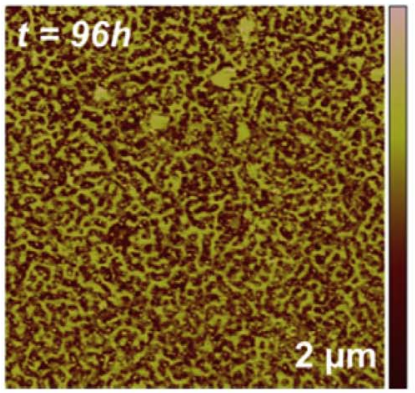

(a)

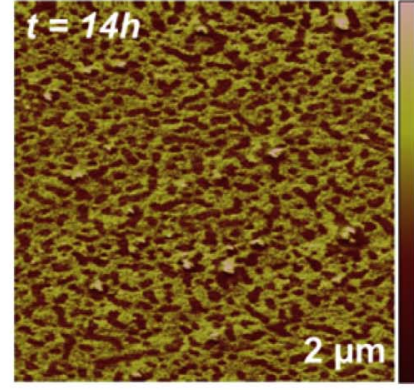

(b)
Fig. 1. AFM tapping mode phase $2 \times 2 \mu \mathrm{m}^{2}$ images of a $45 \mathrm{~nm}$ thickness film of $\mathrm{SBM}_{\mathrm{T}}$ annealed under vacuum at $120^{\circ} \mathrm{C}$ for $96 \mathrm{~h}$ (a) and under air for $14 \mathrm{~h}(\mathrm{~b})$.

great part the morphology. In their work performed on a triblock SBM containing only $6 \%$ of butadiene (see Figs. 3 and 4 in Ref. [13]), the edges of PS lamellae can be partially covered by the PB phase. Here, our interpretation would be that $\mathrm{PB}$ blocks (in higher proportion than in (a)

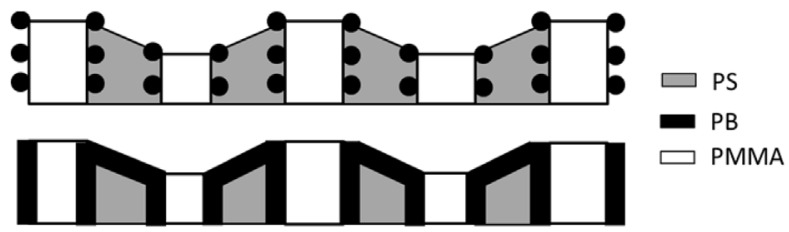

Fig. 2. "Ball at the wall" morphology (a) proposed by Stadler [12,13] for a SBM having weight fractions $\mathrm{w}_{\mathrm{PS}}=0.45, \mathrm{w}_{\mathrm{PB}}=0.06, \mathrm{w}_{\mathrm{PMMA}}=0.49$, (b) proposed for the SBM studied in this work with higher PB content.

Ref. [13]) totally cover the PS phase, and are surrounded by PMMA lamellae perpendicular to the surface (Fig. 2). According to a previous study in our group [14], PS/PMMA blends are characterized by a gold phase corresponding to PMMA (having the highest sub-glassy modulus) whereas PS appear in brown. Here, this would mean that PMMA phase appears in gold whereas the surface PS phase covered with PB appears in brown. We will assume that this interpretation remains valid in the following of this work.

The same experiment was performed under air (Fig. 1b). It appears that the self-assembly process starts faster but is inhibited after about $30 \mathrm{~min}$. This suggests that oxygen influences the $\mathrm{SBM}_{\mathrm{T}}$ (and, as it will be shown later, all kinds of SBM) physicochemical properties detrimental to its ability to self-assemble, which will be investigated in the following.

These first observations were completed by aging experiments on the unpurified commercial grade $\mathrm{SBM}_{\mathrm{T}+\mathrm{D}+\mathrm{Aox}}$ spin-coated and thermally annealed at $120{ }^{\circ} \mathrm{C}$ under vacuum. Here, the presence of diblock alters the nature of the equilibrium morphology (with changes from purely lamellar to cylinders-in-lamellae or lamellae with fluctuations as discussed in Ref. [11]), but the role of oxygen can still be observed on the results presented in Fig. $3 a$ and $b$.

A disordered state is first observed. Under vacuum, $\mathrm{SBM}_{\mathrm{T}+\mathrm{D}+\mathrm{Aox}}$ progressively organizes within the first $2 \mathrm{~h}$ (since morphologies at 2 and $24 \mathrm{~h}$ are very close (Fig. 3a). However, when the sample is annealed under air at $120{ }^{\circ} \mathrm{C}$ (Fig. 3b), the ability of $\mathrm{SBM}_{\mathrm{T}+\mathrm{D}+\mathrm{Aox}}$ to organize is changed. After $1 \mathrm{~h}$, the organization seems progressively to disappear and the material displays a microstructure totally different from the one observed under vacuum with the appearance of a macrophase separation (with domains having a typical size about $100 \mathrm{~nm}-1 \mu \mathrm{m}$ ).

Interestingly, the changes induced by the presence of oxygen are more observable in the blend $\mathrm{SBM}_{\mathrm{T}+\mathrm{D}+\mathrm{AOx}}$ than in the pure triblock $\mathrm{SBM}_{\mathrm{T}}$. As it will be discussed later, a possible explanation is the presence of a higher polybutadiene weight content in the former (33\% vs $20 \%$ respectively).

In the case of manufactured materials reinforced by SBM, the manufacturing process may involve high temperatures (higher than $240{ }^{\circ} \mathrm{C}[11]$ ) at which degradation can occur quite rapidly. We thus investigated if the degradation induced by processing can modify the equilibrium morphology. For that purpose, $\mathrm{SBM}_{\mathrm{T}+\mathrm{D}}$ samples purified from their antioxidants were first oxidized for various times at $120{ }^{\circ} \mathrm{C}$. This temperature was arbitrarily chosen so as to get well distinct aged samples but the issue of the difference between ageing temperature and glass transition of each block will not be addressed here. They were then allowed to self-assemble during an annealing period at $170{ }^{\circ} \mathrm{C}$ (this annealing temperature was also arbitrarily chosen but shall be necessarily below $\mathrm{T}_{\mathrm{ODT}}$ ). The resultant morphology was monitored by AFM (Fig. 4).

One can first notice some small differences between the equilibrium morphology in Figs. 4a and 3a, which may be due, in our mind, to the fact that the purification process (dissolution in chloroform and precipitation in methanol) induces the loss of some short chains. This will not be discussed in the following in further details in the aim of conciseness. The time to reach an equilibrium morphology after a time which is a decreasing function of exposure duration at $120^{\circ} \mathrm{C}$ (Fig. 5): $4 \mathrm{~h} 30 \mathrm{~min}$ for the unaged sample, about $2 \mathrm{~h}$ for the sample aged $30 \mathrm{~min}$ 

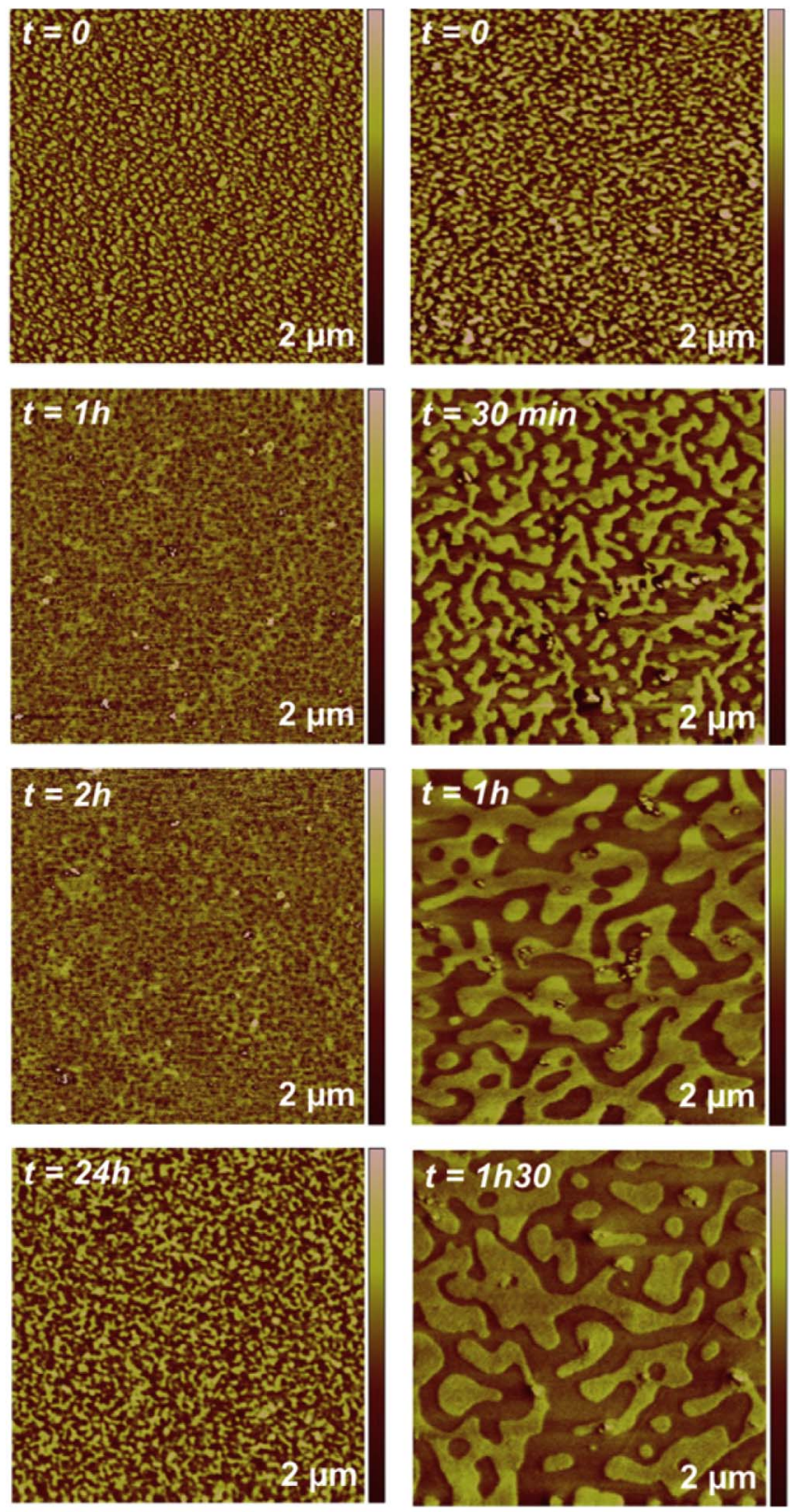

(a)

at about $4 \%$ at high conversion degrees. The polybutadiene curves display the same shape but with a higher value at the plateau: about $12 \%$ for the PB1 and $8 \%$ for PB2. Since existing literature has shown a common reactivity of cis and trans units [17], the difference might be due to the Diffusion Limited Oxidation [18] effect existing between the two samples (masses were each time about $5 \mathrm{mg}$ for PB2 versus about $2 \mathrm{mg}$ for PB1). The gravimetric curve for PS- $b$-PMMA does not display any significant mass increase within the investigated exposure time.

The mass increase corresponds to the reaction between oxygen and alkyl radicals $\left(\mathrm{P}^{\circ}\right)$ generated from the thermal decomposition of unstable species during ageing. The resulting peroxy radicals $\left(\mathrm{POO}^{\circ}\right)$ can either terminate or abstract another hydrogen atom to generate hydroperoxides (POOH). Those later can be considered as key products of oxidative ageing and are easily observable at least in polybutadiene [15]. They can be detected using DSC from the exothermal signal resulting from their thermal decomposition centered ranging from 100 to $250{ }^{\circ} \mathrm{C}$ and centered at $180{ }^{\circ} \mathrm{C}$ (see for example $[15,19,20]$ ). We thus obtained the results presented in Fig. 7 where kinetic curves for hydroperoxides changes display the same induction period (i.e. the time at which they start to be detectable) as observed for the gravimetric curves (about 10-20 min for $\mathrm{PB}$ and more than $100 \mathrm{~min}$ for $\mathrm{SBM}_{\mathrm{T}+\mathrm{D}}$ ). The changes in values display the expected shape $[16,21]$ corresponding to an increase after the induction period, followed by a short plateau and a decrease usually ascribed to the beginning of the substrate consumption [22]. POOH are observed in PB and in SBM, but not in PS- $b$-PMMA even after longer durations (for example $8 \mathrm{~h}$ ) at $120^{\circ} \mathrm{C}$.

Hydroperoxides decomposition is established to result in either chain scissions or crosslinking. These macromolecular changes can be assessed from sol-gel analysis performed at room temperature [23]. The measurements done in chloroform (Fig. 8) show that virgin polybutadienes are fully soluble. For samples aged at $120{ }^{\circ} \mathrm{C}$, an insoluble fraction appears rapidly (for ageing times about $10 \mathrm{~min}$ ) and the gel fraction reaches $80 \%$ after $30 \mathrm{~min}$ of exposure. $\mathrm{SBM}_{\mathrm{T}+\mathrm{D}}$ becomes insoluble after roughly $2 \mathrm{~h}$ ageing at $120{ }^{\circ} \mathrm{C}$, which is the same order of magnitude as the induction time for hydroperoxides build-up.

In $\mathrm{PB}$, the plateau value is clearly below $100 \%$. A possible explanation is that samples undergo crosslinking but some chain scissions reactions compensate (at least in part) the formation of gel, which explains why the $\mathrm{PB}$ does not become fully insoluble at high exposure times.

In $\mathrm{SBM}_{\mathrm{T}+\mathrm{D}}$, the plateau value is even lower. In other words, it suggests that the rigid phase (PS and PMMA blocks) undergoes chain scissions resulting in the generation of soluble short chains.

In the case of aged materials, the weigth fractions of S, B and M connected to the gel are:

$\mathrm{w}_{\mathrm{Sg}}=\mathrm{w}_{\mathrm{SO}} \times\left(1-\mathrm{s}_{\mathrm{S}}\right)$

$\mathrm{w}_{\mathrm{Mg}}=\mathrm{w}_{\mathrm{MO}} \times\left(1-\mathrm{s}_{\mathrm{M}}\right)$

$\mathrm{w}_{\mathrm{Bg}}=\mathrm{w}_{\mathrm{B} 0} \times\left(1-\mathrm{s}_{\mathrm{B}}\right) \sim 0.8 \cdot \mathrm{w}_{\mathrm{B} 0}$ (according to Fig. 8).

where $s_{S}, s_{M}$ and $s_{B}$ correspond to the fraction of PS, PMMA and PB that became soluble after chain scissions.

The overall insoluble fraction is given by:

$2 \mathrm{~h}$ at $120{ }^{\circ} \mathrm{C}$ (Fig. 4d) has lost its ability to generate a morphology comparable to the one observed in Figs. 1 and 3, i.e. no self-assembly was observed. AFM pictures seem rather to indicate a macrophase separation with size domains about $100 \mathrm{~nm}$ (i.e. clearly higher than in Fig. 4a).

\subsection{Study of the SBM degradation mechanism}

The ageing at $120{ }^{\circ} \mathrm{C}$ under air of a $\mathrm{SBM}_{\mathrm{T}+\mathrm{D}}$ material was monitored using TGA and compared with purified PB1 and PB2 and PS- $b$-PMMA. According to Fig. 6, the gravimetric curve for $\mathrm{SBM}_{\mathrm{T}+\mathrm{D}}$ displays the classical sigmoidal shape encountered in the case of auto-accelerated oxidation of hydrocarbon polymers $[15,16]$. The curve almost plateaus

$\mathrm{w}_{\mathrm{g}}=\mathrm{w}_{\mathrm{Bg}}+\mathrm{w}_{\mathrm{Sg}}+\mathrm{w}_{\mathrm{Bg}}$

$0.5=0.8 \times 0.33+0.33 \times\left(1-s_{S}\right)+0.33 \times\left(1-s_{M}\right)$

Let us assume, in a first approach, that $s_{S}$ and $s_{M}$ are the same. It leads to $s_{M}=s_{S}=0.64$. In other words, it can be assumed that the gel is made of roughly $50 \% \mathrm{~PB}$ and $25 \%$ each of PS and PMMA.

$\mathrm{T}_{\mathrm{g}}$ changes were tentatively monitored by DSC to confirm this last assessment. Virgin $\mathrm{SBM}_{\mathrm{T}+\mathrm{D}}$ sample display 3 glass transitions (Table 1) which were ascribed from Refs. $[11,12]$. $\mathrm{T}_{\mathrm{g} 1}$ is very low and corresponds to the PB block. $\mathrm{T}_{\mathrm{g} 2}$ corresponds to the PS block. Its value is lower than observed in bulk PS, presumably because PS chains are short [24]. $\mathrm{T}_{\mathrm{g} 3}$ is the highest one and corresponds to syndiotactic PMMA 

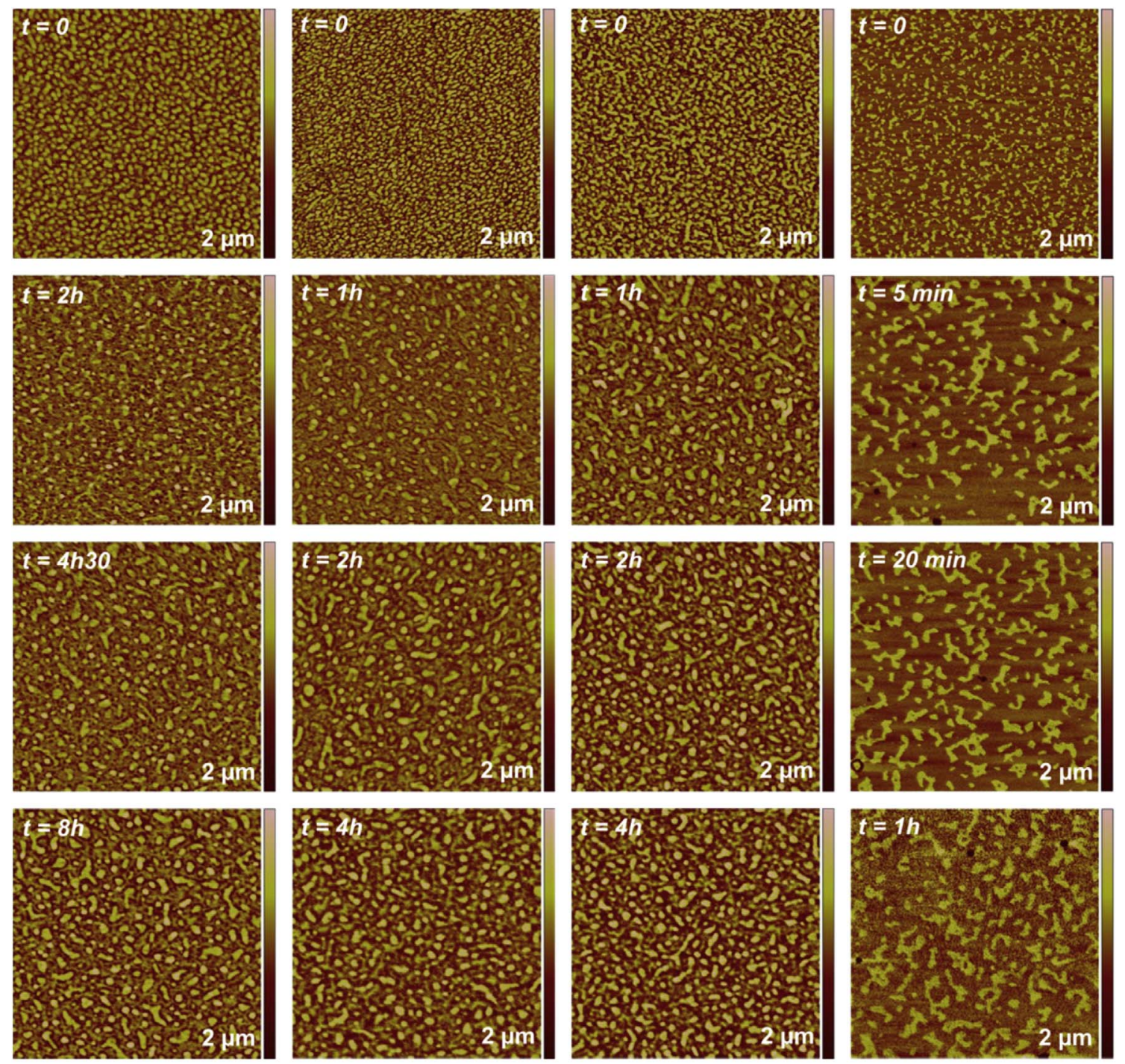

(a) unaged

(b) aged $30 \mathrm{~min}$ at $120^{\circ} \mathrm{C}$

(c) aged $1 \mathrm{~h}$ at $120^{\circ} \mathrm{C}$

(d) aged $2 \mathrm{~h}$ at $120^{\circ} \mathrm{C}$

Fig. 4. AFM tapping mode phase $2 \times 2 \mu \mathrm{m}^{2}$ images of a $45 \mathrm{~nm}$ thickness film of $S_{B M_{T+D}}$ first thermally aged at $120^{\circ} \mathrm{C}$ under air during $0,30 \mathrm{~min}, 1 \mathrm{~h}, 2 \mathrm{~h}$ and subsequently annealed under vacuum at $170{ }^{\circ} \mathrm{C}$.

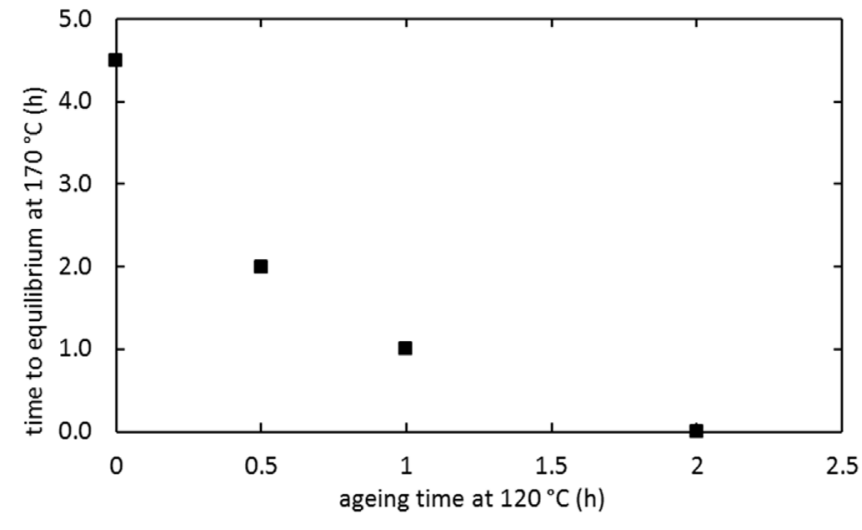

Fig. 5. Effect of oxidation on time to reach the final morphology (in $\mathrm{SBM}_{\mathrm{T}+\mathrm{D}}$ ).

obtained from anionic polymerization [25].

The PB glass transition temperature may display a slight increase, which can be explained by the previously identified crosslinking, and glass transition temperature of the two other blocks decreases

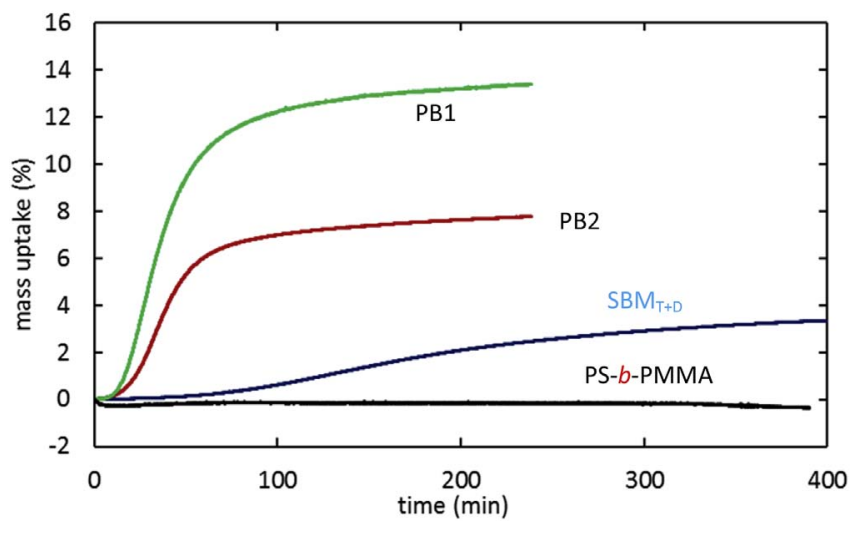

Fig. 6. Gravimetric curves recorded by TGA under air at $120^{\circ} \mathrm{C}$.

confirming that both PMMA and PS undergo chain scissions.

This was in part confirmed by GPC measurements of aged samples (Fig. 9) below the "gel point" i.e. less than 100 min (Fig. 8). Chromatograms display a main peak which stays centered at the same retention 


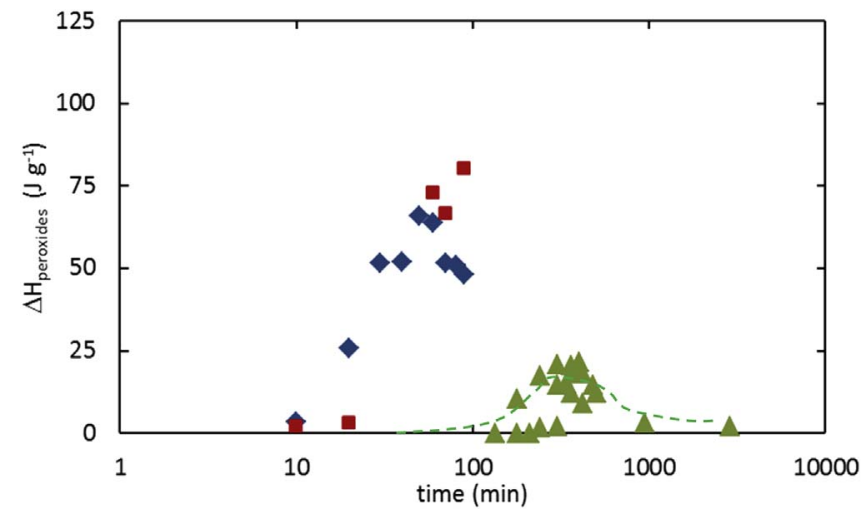

Fig. 7. Maximal enthalpy associated to hydroperoxides decomposition for $\operatorname{SBM}_{\mathrm{T}+\mathrm{D}}(\mathbf{A})$, PB1 $(\diamond)$, PB2 $(\square)$ versus exposure time at $120^{\circ} \mathrm{C}$. NB: data for $\mathrm{SBM}_{\mathrm{T}+\mathrm{D}}$ come from several series of data which might explain this scattering. Dashed lines are guides to the eyes.

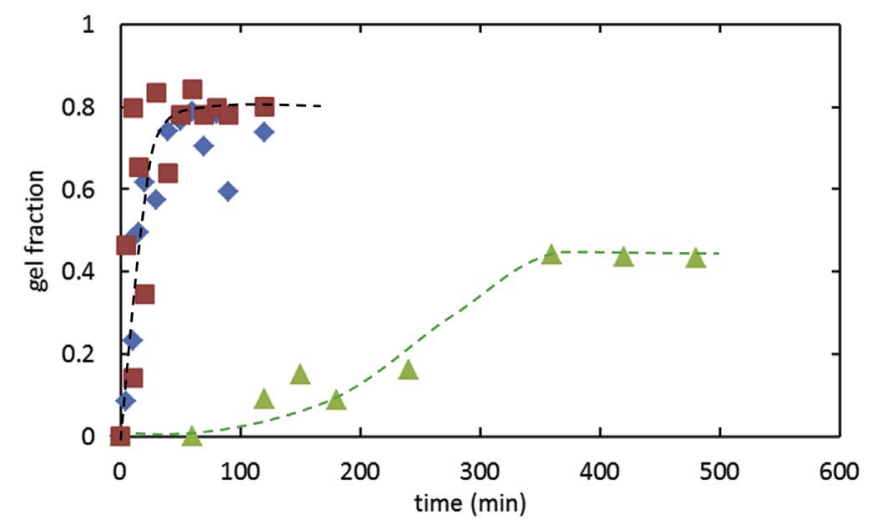

Fig. 8. Sol-gel fraction for $\mathrm{SBM}_{\mathrm{T}+\mathrm{D}}(\boldsymbol{\Lambda}), \mathrm{PB} 1(\diamond), \mathrm{PB} 2(\square)$ versus exposure time at $120^{\circ} \mathrm{C}$. Dashed lines are guide to the eyes.

Table 1

Changes of $\mathrm{T}_{\mathrm{g}}$ in $\mathrm{SBM}_{\mathrm{T}+\mathrm{D}}$ after several thermal oxidation exposures.

\begin{tabular}{llll}
\hline & $\mathbf{T}_{\mathrm{g} 1}\left({ }^{\circ} \mathrm{C}\right)$ & $\mathbf{T}_{\mathrm{g} 2}\left({ }^{\circ} \mathrm{C}\right)$ & $\mathbf{T}_{\mathrm{g} 3}\left({ }^{\circ} \mathrm{C}\right)$ \\
\hline 0 & -62 & 85 & 130 \\
$5 \mathrm{~h} 30$ & -61 & 67 & 123 \\
$8 \mathrm{~h} 20$ & -59 & 67 & 114 \\
\hline
\end{tabular}

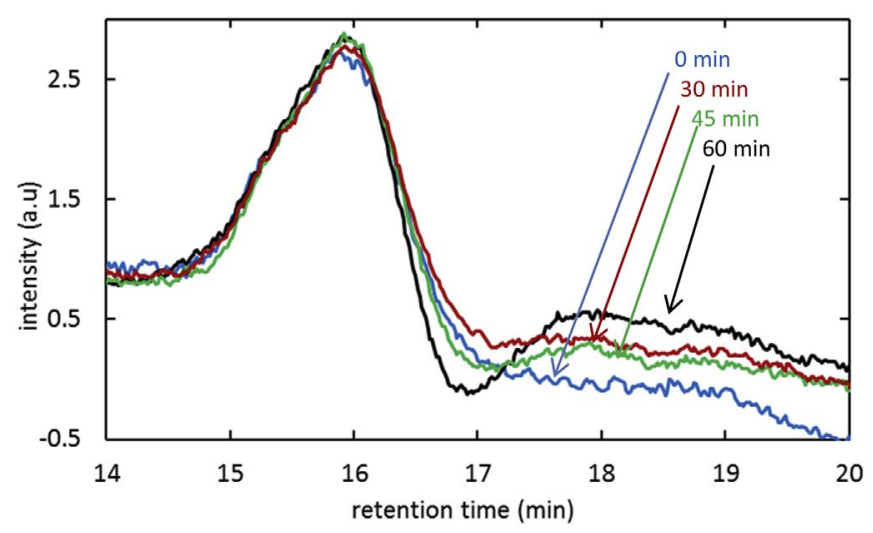

Fig. 9. GPC chromatograms in $\mathrm{TCB}$ of $\mathrm{SBM}_{\mathrm{T}+\mathrm{D}}$ thermally oxidized at $120{ }^{\circ} \mathrm{C}$ under air during $0,30,45$ and $60 \mathrm{~min}$.

time (16 min) which is due to $\mathrm{SBM}_{\mathrm{T}+\mathrm{D}}$. The most striking result is that the molar mass distribution of soluble $\mathrm{SBM}_{\mathrm{T}+\mathrm{D}}$ becomes narrower while a « tail » at retention time close to 18-19 min progressively increases. This latter would be testimony to the existence of short chains coming from chain scissions processes.

FTIR analyses of the soluble part extracted from aged $\mathrm{SBM}_{\mathrm{T}+\mathrm{D}}$ also tend to confirm the existence of chain scissions and are presented in 'Appendix B'.

\section{Discussion}

The aim of this section is to comment on the mechanisms of oxidation of SBM triblock terpolymer and their possible consequences on the self-assembly ability.

\subsection{On the oxidation mechanism of SBM}

From the relative proportions of each block, one sees that the weight fraction of $\mathrm{PB}$ in $\mathrm{SBM}_{\mathrm{T}+\mathrm{D}}$ is close to $33 \%$. Since the SBM self assembles rather fast even at $120{ }^{\circ} \mathrm{C}$ under air (Fig. 3), the degradation mechanisms of each block can be considered as independent of the degradation occurring in others blocks. It is hence not surprising that the maximal enthalpy observed for $\mathrm{POOH}$ decomposition is about $25 \mathrm{~J} \mathrm{~g}^{-1}$ in SBM compared to $75 \mathrm{~J} \mathrm{~g}^{-1}$ in $\mathrm{PB}$ (Fig. 7) and the approximate value of the plateau observed for TGA measurement is about $13 \%$ for PB compared to about $4 \%$ for $\mathrm{SBM}_{\mathrm{T}+\mathrm{D}}$ (Fig. 6).

The most significant difference between $\mathrm{SBM}_{\mathrm{T}+\mathrm{D}}$ and $\mathrm{PB}$ is the induction period duration (about $10 \mathrm{~min}$ for $\mathrm{POOH}$ build-up and gel in $\mathrm{PB}$ vs about $100 \mathrm{~min}$ in $\mathrm{SBM}_{\mathrm{T}+\mathrm{D}}$ ). Let us recall that the main source of radicals creation during thermal ageing of polymer is the direct thermolysis of unstable bonds and the thermally induced decomposition of hydroperoxides. It is well documented that this later can be accelerated by the presence of residual metallic catalysts. Long chain polybutadienes are usually synthetized by coordination polymerization involving various metallic compounds [26,27] whereas triblock terpolymers such as SBM are obtained from anionic polymerization [28,29]. In other words, the relative fastness of $\mathrm{PB}$ oxidation compared to $\mathrm{SBM}_{\mathrm{T}+\mathrm{D}}$ would thus be explained by the negative influence of polymerization metallic catalysts on thermo-oxidative stability [30].

Let us now turn to the oxidation mechanisms occurring in each block. The driving force of oxidative mechanism is the abstraction of hydrogens atoms driven by the bond dissociation energies (BDE) of the possible sites for radical attacks:

- $\mathrm{BDE}_{\mathrm{C}-\mathrm{H}}=355 \mathrm{~kJ} \mathrm{~mol}^{-1}$ for cumene [31] and could be used as an approximate for the BDE of $\mathrm{C}-\mathrm{H}$ in PS blocks

- $\mathrm{BDE}_{\mathrm{C}-\mathrm{H}}=341 \mathrm{~kJ} \mathrm{~mol}^{-1}$ for allylic C-H in alkenes [32] and could be used as an approximate for the BDE of $\mathrm{C}-\mathrm{H}$ in PB blocks

- $\mathrm{BDE}_{\mathrm{C}-\mathrm{H}}$ is not reported to our knowledge in PMMA, but it seems that it must not be too far from the value observed for any aliphatic in hydrocarbon compounds, i.e. $390 \mathrm{~kJ} \mathrm{~mol}^{-1}$ [32].

It is then not surprising that PB blocks in SBM are the most oxidizable because of the highest sensitivity of $\mathrm{C}-\mathrm{H}$ to radical attack.

The next step is to focus on the nature of degradation product (at the macromolecular level).

In $\mathrm{PB}$, radicals are created in $\alpha$ position of double bonds. The mechanisms were investigated in depth and it is clear that the main route is crosslinking [32,33] as verified here by the sol-gel analysis results presented in Fig. 8. The existence of some minor chain scissions is also possible (as proposed in Scheme 1) and explains why the sol-gel fraction does not reach $100 \%$ for oxidized $\mathrm{PB}$.

The oxidation of SBM is thus expected to generate short chains such as PS- $b$-PB or PB- $b$-PMMA diblocks coming from the chain scissions in PB block, or short PMMA or PS chains coming from the oxidation occurring in the corresponding blocks. The corresponding mechanisms are recalled in 'Appendix C'. It is noteworthy that the ageing tests performed on PS-b-PMMA block copolymer showed those materials are rather stable in the investigated timescale and temperatures. However, literature reports the degradation of poly(styrene-b-butadiene) films 


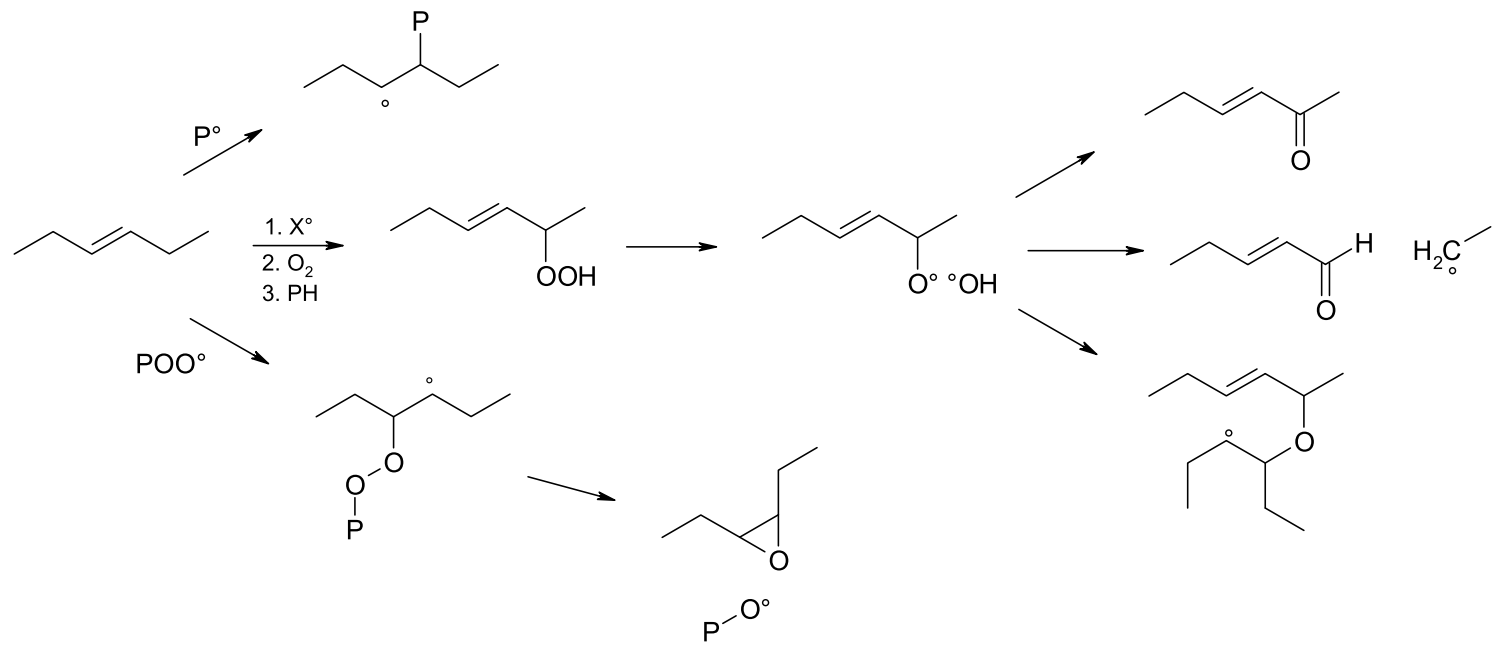

Scheme 1. Degradation mechanism of PB block occurring in the presence of oxygen.

[34] or HIPS (where PS is blended with a PB phase) in which oxidation starts in the butadiene phase, where double bonds are rapidly consumed [8], and later induced the degradation of PS phase, where $\mathrm{T}_{\mathrm{g}}$ was shown to decrease which is testimony to a chain scission process. The same was reported for the oxidation of PMMA/rubber blends which starts in the rubber phase resulting in radicals initiating the oxidation of the PMMA phase, presumably mainly at the interfaces [35]. In any case, let us recall that GPC results evidence that short chains are generated quite rapidly.

In the next part, we will discuss the possible consequences of those mechanisms on the self-assembly ability of the polymer.

\subsection{On the effect of triblock oxidation on its self-assembly}

The miscibility of a blend of polymers is predicted from the value of mixing free energy of mixing:

$\Delta G_{m}=\Delta H_{m}-\mathrm{T} \Delta S_{m}$

where the enthalpy of mixing is given by: $\Delta H_{\mathrm{m}}=\mathrm{RT} \chi_{\mathrm{AB}} \phi_{\mathrm{A}} \phi_{\mathrm{B}}$ where $\chi_{\mathrm{AB}}$ is the Flory-Huggins interaction parameter for the A-B mixture. The enthalpic term (triggered by $\chi_{\mathrm{AB}}$ ) is generally positive in the case of polymer blends. It means that interactions between $\mathrm{A}$ and $\mathrm{B}$ are repulsive and that mixing is not thermodynamically favored. In the case of thermo-oxidative ageing, $\chi_{\mathrm{AB}}$ is expected to change due to the buildup of stable polar products such as carbonyls. Its estimation for example from the solubility parameters values of each block was recently questioned [36]. However, the comparison of Figs. 7 and 8 shows the macromolecular changes are detected at quite short exposure times where hydroperoxide concentration is negligible. Fig. 5 also shows that the kinetics of self-assembly is changed at low conversion degree. It can thus be supposed that $\chi_{\mathrm{AB}}$ would remain almost constant during the investigated time scale.

$\Delta S_{\mathrm{m}}$ is the entropy of mixing, which is expressed from statistical theory by:

$\Delta S_{m}=-R \cdot\left(\frac{\phi_{A}}{N_{A}} \cdot \ln \phi_{A}+\frac{\phi_{B}}{N_{B}} \cdot \ln \phi_{B}\right)$

where $\phi_{\mathrm{i}}$ and $\mathrm{N}_{\mathrm{i}}$ are respectively the volume phase ratio and the polymerization degree of i chains. $\Delta S_{\mathrm{m}}$ is positive but close to 0 . It decreases with chain length. In other words, if chains undergo scissions, the (favorable) entropic contribution to mixing will increase. This effect may be enhanced by the positive role of short chain segments generated by chain scissions which can act as "plasticizer" increasing the mobility of the system. This is for example illustrated when comparing the kinetics of organization of pure SBM triblock (Fig. 1) and SBM triblock containing residual SB diblock (Fig. 3). It explains the results in Fig. 3 where slightly oxidized samples (where hydroperoxides concentrations are negligible, and below the "gel" point of butadiene block) self-assemble faster than unaged analogues.

At higher conversion degrees, butadiene blocks are crosslinked while the styrene and methyl methacrylate blocks have undergone a significant amount of chain scissions. Due to chain scissions, PS, PMMA and $\mathrm{PB}$ blocks, that are in essence immiscible, will undergo a phase separation process observed in Figs. 1 and 2 at high annealing time under air. Then, crosslinking in the PB phase will decrease the number of accessible configurations of chains, i.e. the entropy of the mixed state. The system will hence become frozen at high exposure times.

\section{Conclusions}

This work deals with the thermal ageing of a triblock terpolymer, poly(styrene- $b$-butadiene- $b$-methyl methacrylate) used for improving the impact resistance of brittle polymers. Its oxidation mechanism was mainly investigated at the macromolecular level. As expected from the study of ageing of model systems, PS and PMMA blocks undergo chain scission whereas PB blocks mainly crosslink. We were interested in the possible consequences of those macromolecular-induced changes on the final SBM morphology. It is observed that at low conversion degree, the effect of chain scissions occurring in PS and PMMA block predominate, so that the system self-assembles faster without significant changes on the final morphology. At very high conversion degree, SBM becomes a gel because of crosslinking occurring in polybutadiene block, so that it can no longer self-organize, whereas further chain scissions lead to a well-marked phase separation. From a theoretical point of view, establishing the effect of oxidation on the thermodynamics of self-assembly remains a challenge. From a more practical point of view, this work shows that the degradation of SBM may alter its final microstructure and the expected mechanical properties of the blended materials.

\section{Acknowledgments}

Carnot Arts is acknowledged for funding the PL-GPC $220^{\circ}$ through the «Carnot-CEQUAM project» (2010). Arkema is acknowledged for having supplied SBM materials. 


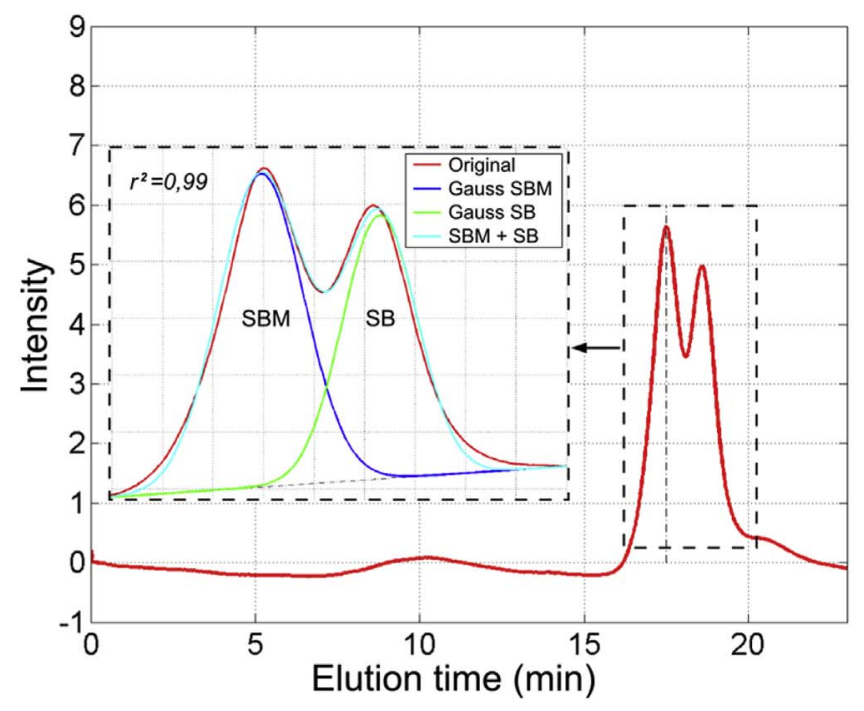

(a)

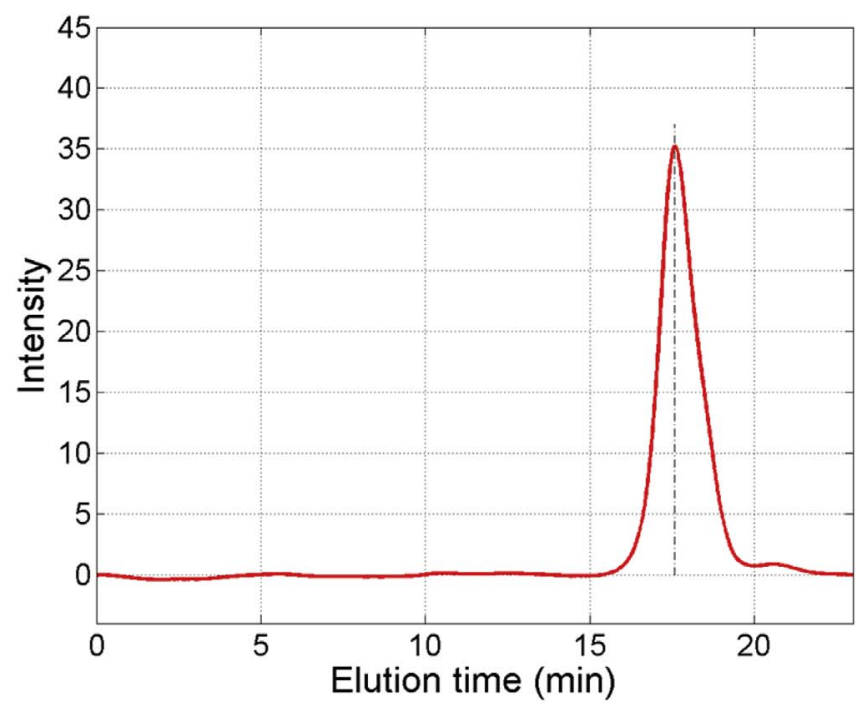

(b)

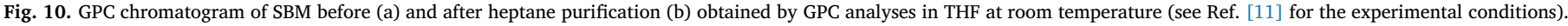
NB: the difference with chromatograms presented in Fig. 9 may originate from elution solvent and temperature analysis.

\section{Appendix B. FTIR analyses of soluble part of oxidized SBM}

FTIR spectra were recorded in transmission mode by casting the soluble part of aged SBM on a KBr plate. Spectra were recorded using a Frontier 100 apparatus (Perkin Elmer). They were obtained by averaging 4 scans with $4 \mathrm{~cm}^{-1}$ resolution.

The FTIR spectra of soluble part of oxidized SBM are presented in Fig. 11. In the carbonyl region, the main carbonyl band ascribed to PMMA is clearly visible. Two shoulders increase with ageing time:

- a shoulder at ca $1690 \mathrm{~cm}^{-1}$, for which the best explanation is the formation of aryl ketone groups coming from the oxidation of PS blocks [37] or of unsaturated ketones coming from the oxidation of PB segments.

- a shoulder at $1775 \mathrm{~cm}^{-1}$ for which several explanations can be proposed: diphenylanhydride generated during oxidation of PS [38] or gamma lactones observed during the oxidative ageing of elastomers [38]. The oxidation of methoxy groups in PMMA also gives an anhydride with an absorption in this wavenumber range. Last, a small signal at $1640 \mathrm{~cm}^{-1}$ is observed, testimony of PMMA blocks degradation [39].

One can also observe that the intensity of the peak ascribed to $=\mathrm{C}-\mathrm{H}$ stretching at $965 \mathrm{~cm}^{-1}$ decreases. It suggests that the chains present in the soluble part becomes poorer and poorer in double bonds, meaning that these ones stay in the gel part or disappear by a crosslinking process.

In conclusion, the soluble part seems to contain some degradation product of PS and PMMA blocks. Even if it is an indirect evidence, this should mean that soluble part is made either of "pure" PS or PMMA short chain segments coming from scissions in the corresponding blocks, or maybe PS- $b$ - 
PB or PB-b-PMMA diblock copolymers coming from chain scissions in the polybutadiene segment.

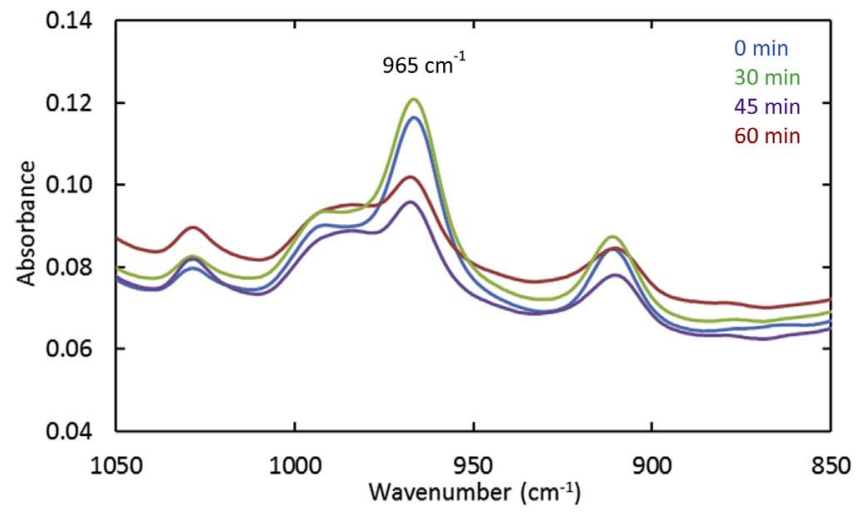

(a)

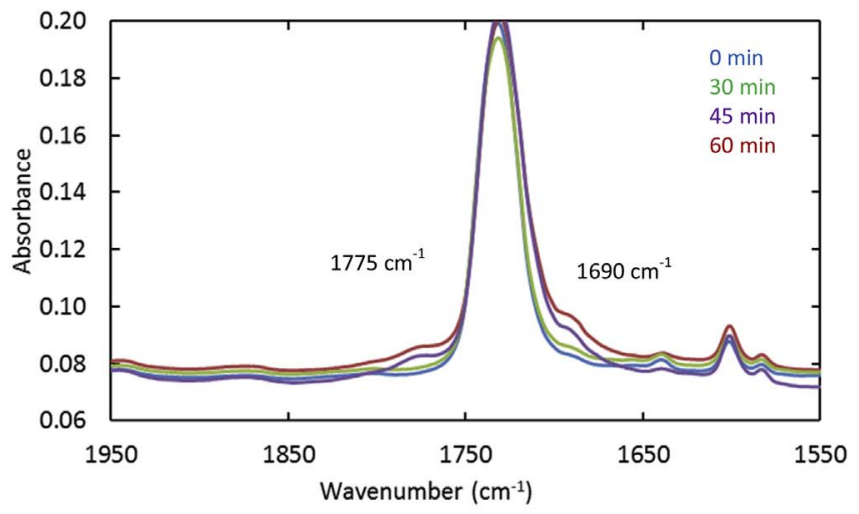

(b)

Fig. 11. FTIR spectra of soluble part of oxidized SBM after several exposure times (a) in the fingerprint region, (b) in the carbonyl region.

\section{Appendix C. Mechanism of degradation in PS and PMMA blocks}

Due to steric hindrance of the lateral substituents, the polymerization enthalpy of styrene and methyl methacrylate are reported to be lower than in many other polymers [40]. It results in a lower monomer-monomer bond enthalpy which explains why their thermal ageing yields to a (very) high quantity of monomer [41] and their thermal oxidation generates mainly chain scissions [42]. An example of unzip mechanism is given in Scheme 2 and the same is presumed to occur in PS blocks.<smiles>C=C(C)C(=O)OC</smiles><smiles>COC(=O)C(C)(C)CC(C)(C)C</smiles>

Scheme 2. Degradation mechanism of PMMA block occurring in the absence of oxygen.

However, it seems to us that those mechanisms do not occur in the timescale under study since PS-b-PMMA does not display evidences of chain scission.

It is also very often proposed that PMMA would react rather by a depolymerization mechanism unzipping the chain instead of oxidation [43]. However, it is sure that in presence of oxygen, it is expected to react quite fast with radicals (the rate constant is close to $10^{9} 1 \mathrm{~mol}^{-1} \mathrm{~s}{ }^{-1}$ i.e. among the highest values known in radical chemistry [44]). The oxidative mechanism is here also expected to generate chain scissions (Scheme 3a). Alternatively, the oxidation of side methyl can generates the anhydrides observed in Ref. [45] (Scheme 3b) but the occurrence of this mechanism in the investigated time scale at the temperature under study remains speculative. 


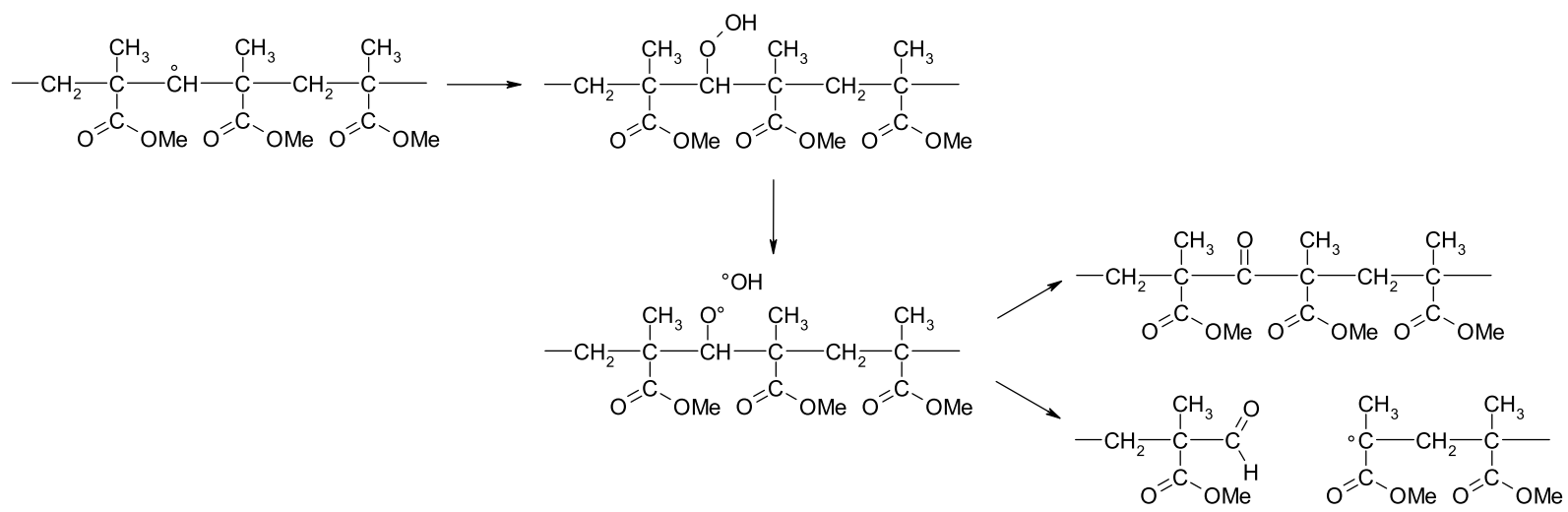

(a)

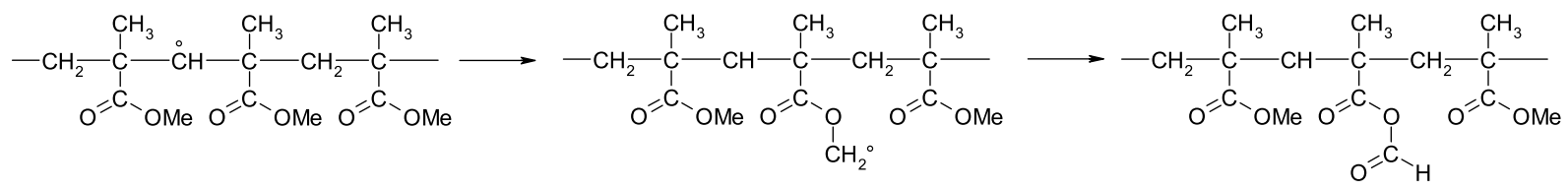

(b)

Scheme 3. Degradation mechanism of PMMA blocks occurring in the presence of oxygen (a) occurring on the main chain, (b) leading to a side chain anhydride.

Let us now turn to the PS block. It is well documented that the degradation of PS first involved its tertiary C-H group, which reacts to give a hydroperoxide [38]. This later decomposes into an alkoxy which reacts by a beta scission process. In other words, PS oxidative degradation is expected to give chain scissions [46] (Scheme 4).<smiles>CCC(CC(C)c1ccccc1)c1ccccc1</smiles>

Scheme 4. Degradation mechanism of PS block occurring in the presence of oxygen.

\section{References}

[1] S.B. Darling, Directing the self-assembly of block copolymers, Progr. Polym. Sci. 32 (2007) 1152-1204.

[2] F.S. Bates, G.H. Fredrickson, Block copolymers - designer soft materials, Phys. Today 52 (1999) 32-38.

[3] L. Leibler, Theory of microphase separation in block copolymers, Macromolecules 13 (1980) 1602-1617.

[4] C.D. Han, J. Kim, J.K. Kim, Determination of the order-disorder transition temperature of block copolymers, Macromolecules 22 (1989) 383-394.

[5] T. Gómez-del Río, A. Salazar, R.A. Pearson, J. Rodríguez, Fracture behaviour of epoxy nanocomposites modified with triblock copolymers and carbon nanotubes, Compos. Part B Eng. 87 (2016) 343-349.

[6] R. Bahrami, T.I. Löbling, H. Schmalz, A.H.E. Müller, V. Altstädt, Synergistic effects of Janus particles and triblock terpolymers on toughness of immiscible polymer blends, Polymer 109 (2017) 229-237.

[7] K. Xiang, X. Wang, G. Huang, J. Zheng, J. Huang, G. Li, Thermal ageing behavior of styrene-butadiene random copolymer: a study on the ageing mechanism and relaxation properties, Polym. Degrad. Stab. 97 (2012) 1704-1715.

[8] C. Adam, J. Lacoste, J. Lemaire, Photo-oxidation of elastomeric materials: Part II-photo-oxidation of styrene-butadiene copolymer, Polym. Degrad. Stab. 26 (1989) 269-284.

[9] S.B. Munteanu, M. Brebu, C. Vasile, Thermal and thermo-oxidative behaviour of butadiene-styrene copolymers with different architectures, Polym. Degrad. Stab. 89 (2005) 501-512.

[10] E. Serrano, A. Zubeldia, M. Larrañaga, P. Remiro, I. Mondragon, Effect of different thermal treatments on the self-assembled nanostructures of a styrene-butadiene-styrene star block copolymer, Polym. Degrad. Stab. 83 (2004) 495-507.

[11] S. Roland, G. Miquelard-Garnier, M. Gervais, A. Guinault, C. Sollogoub, Controlling the order of triblock copolymer via confinement induced by forced self-assembly, Mater. Today Comm. 6 (2016) 37-43.

[12] T. Périé, A.-C. Brosse, S. Tencé-Girault, L. Leibler, Mechanical and electrical properties of multi walled carbon nanotube/ABC block terpolymer composites, Carbon
50 (2012) 2918-2928.

[13] W. Stocker, J. Beckmann, R. Stadler, J.P. Rabe, Surface reconstruction of the lamellar morphology in a symmetric poly(styrene-block-butadiene-block-methyl methacrylate) triblock copolymer: a tapping mode scanning force microscope study, Macromolecules 29 (1996) 7502-7507.

[14] A. Bironeau, T. Salez, G. Miquelard-Garnier, C. Sollogoub, Existence of a critical layer thickness in PS/PMMA nanolayered films, Macromolecules 50 (2017) 4064-4073.

[15] M. Coquillat, J. Verdu, X. Colin, L. Audouin, R. Nevière, Thermal oxidation of polybutadiene. Part 1: effect of temperature, oxygen pressure and sample thickness on the thermal oxidation of hydroxyl-terminated polybutadiene, Polym. Degrad. Stab. 92 (2007) 1326-1333.

[16] V. Defauchy, P.Y. Le Gac, A. Guinault, J. Verdu, G. Recher, R. Drozdzak, E. Richaud, Kinetic analysis of polydicyclopentadiene oxidation, Polym. Degrad. Stab. 142 (2017) 169-177.

[17] C. Adam, J. Lacoste, J. Lemaire, Photo-oxidation of elastomeric materials. Part 1-photo-oxidation of polybutadienes, Polym. Degrad. Stab. 24 (1989) 185-200.

[18] M.C. Celina, Review of polymer oxidation and its relationship with materials performance and lifetime prediction, Polym. Degrad. Stab. 98 (2013) 2419-2429.

[19] Y. Ouldmetidji, L. Gonon, S. Commereuc, V. Verney, A differential scanning calorimetry method to study polymer photoperoxidation, Polym. Test. 20 (2001) $765-768$.

[20] E. Richaud, F. Farcas, B. Fayolle, L. Audouin, J. Verdu, Hydroperoxide titration by DSC in thermally oxidized polypropylene, Polym. Test. 25 (2006) 829-838.

[21] S. Commereuc, S. Bonhomme, V. Verney, J. Lacoste, Photooxidation of polyoctenamer: viscoelastic assessment of gel formation, Polymer 41 (2000) 917-923.

[22] E. Richaud, F. Farcas, B. Fayolle, L. Audouin, J. Verdu, Hydroperoxide build-up in the thermal oxidation of polypropylene - a kinetic study, Polym. Degrad. Stab. 92 (2007) 118-124.

[23] M. Baba, J.-L. Gardette, J. Lacoste, Crosslinking on ageing of elastomers: I. Photoageing of EPDM monitored by gel, swelling and DSC measurements, Polym. Degrad. Stab. 63 (1999) 121-126.

[24] P. Claudy, J.M. Létoffé, Y. Camberlain, J.P. Pascault, Glass transition of polystyrene versus molecular weight, Polym. Bull. 9 (1983) 208-215.

[25] X. Lu, B. Jiang, Glass transition temperature and molecular parameters of polymer, 
Polymer 32 (1991) 471-478.

[26] N.M.T. Pires, F.M.B. Coutinho, M.A.S. Costa, Synthesis and characterization of high cis-polybutadiene: influence of monomer concentration and reaction temperature, Eur. Pol. J. 40 (2004) 2599-2603.

[27] R.P. Burford, Polymerization of butadiene using ziegler-natta catalysts-recent developments, J. Macromol. Sci. A 17 (1982) 123-139.

[28] C.M. Fernyhough, D. Pantazis, S. Pispas, N. Hadjichristidis, The micellar behavior of linear triblock terpolymers of styrene (S), isoprene (I), and methyl methacrylate (MMA) in selective solvents for PS and PMMA, Eur. Pol. J. 40 (2004) 237-244.

[29] R. Kabir, J. Albuerne, P.F.W. Simon, V. Filiz, C. Abetz, H. Böttcher, J. Perlich, V. Abetz, Deformation and orientation behavior of polystyrene-b-polybutadiene-bpoly(methyl methacrylate) triblock terpolymers: influence of polybutadiene microstructures and the molar masses, Polymer 54 (2013) 673-684.

[30] E.M. Hoàng N.S. Allen, C.M. Liauw, E. Fontán, P. Lafuente, The thermo-oxidative degradation of metallocene polyethylenes. Part 1: long-term thermal oxidation in the solid state, Polym. Degrad. Stab. 91 (2006) 1356-1362.

[31] E.T. Denisov, I.B. Afanas'ev, Oxidation and Antioxidants in Organic Chemistry. And Biology, Taylor \& Francis, 2005 Chap 2. Chain Mechanism of Liquid-Phase Oxidation of Hydrocarbons. Table 3.11.

[32] M. Coquillat, J. Verdu, X. Colin, L. Audouin, R. Nevière, Thermal oxidation of polybutadiene. Part 3: molar mass changes of additive-free non-crosslinked polybutadiene, Polym. Degrad. Stab. 92 (2007) 1343-1349.

[33] A. Akbaş, S. Aksoy, N. Hasırc1, Effects of thermal ageing on the properties and lifetime prediction of hydroxyl-terminated polybutadiene, Polymer 35 (1994) 2568-2572.

[34] E.F.-J. Rettler, T. Rudolph, A. Hanisch, S. Hoeppener, M. Retsch, U.S. Schubert, F.H. Schacher, UV-induced crosslinking of the polybutadiene domains in lamellar polystyrene-block-polybutadiene block copolymer films - an in-depth study, Polymer 53 (2012) 5641-5648.

[35] R. Broska, N.C. Billingham, P.K. Fearon, Accelerating effect of poly(methyl methacrylate) on rubber oxidation, Part 1: a chemiluminescence study, Polym. Degrad. Stab. 93 (2008) 1100-1108.

[36] G. Miquelard-Garnier, S. Roland, Beware of the Flory parameter to characterize polymer-polymer interactions: a critical reexamination of the experimental literature, Eur. Polym. J. 84 (2016) 111-124.

[37] J.-L. Gardette, B. Mailhot, J. Lemaire, Photooxidation mechanisms of styrenic polymers, Polym. Degrad. Stab. 48 (1995) 457-470.

[38] M. Piton, A. Rivaton, Photooxidation of polybutadiene at long wavelengths $(\lambda>300 \mathrm{~nm})$, Polym. Degrad. Stab. 53 (1996) 343-359.

[39] J. Kowalonek, Surface studies of UV-irradiated poly(vinyl chloride)/poly(methyl methacrylate) blends, Polym. Degrad. Stab. 133 (2016) 367-377.

[40] D.E. Roberts, Heat of polymerization. A summary of published values and their relation to structure, J. Res. Nat. Bur. Stand 44 (1950) 221-232.

[41] W. Kaminsky, M. Predel, A. Sadiki, The 42nd IUPAC microsymposium on degradation, stabilisation and recycling of polymers, and the 2nd feedstock recycling of polymers by pyrolysis in a fluidised bed, Polym. Degrad. Stab. 85 (2004) 1045-1050.

[42] G. Madras, V. Karmore, Continuous distribution kinetics for oxidative degradation of PMMA in solution, Polym. Degrad. Stab. 72 (2001) 537-541.

[43] M. Celina, D.K. Ottesen, K.T. Gillen, R.L. Clough, FTIR emission spectroscopy applied to polymer degradation, Polym. Degrad. Stab. 58 (1997) 15-31.

[44] E.T. Denisov, I.B. Afanas'ev, Oxidation and Antioxidants in Organic Chemistry. And Biology, Taylor \& Francis, 2005 Chap 2. Chain Mechanism of Liquid-Phase Oxidation of Hydrocarbons. Table 2.4.

[45] J. Kowalonek, Surface studies of UV-irradiated poly(vinyl chloride)/poly(methyl methacrylate) blends, Polym. Degrad. Stab. 133 (2016) 367-377.

[46] F. Vilaplana, A. Ribes-Greus, S. Karlsson, Degradation of recycled high-impact polystyrene. Simulation by reprocessing and thermo-oxidation, Polym. Degrad. Stab. 91 (2006) 2163-2170. 